\title{
Prevention of Adhesions by PL/PG after Adhesiolysis
}

\section{Akerberg D, Posaric Bauden M, Isaksson K, Andersson R and Tingstedt $B^{*}$}

Department of Surgery, Clinical Sciences, Lund University, Lund, Sweden

\begin{abstract}
Background: Previous studies of differently charged polypeptides, Poly-L-lysine (PL) and Poly-L-Glutamate (PG) have shown promising results, reducing postoperative adhesions. This study aimed to investigate the possible anti adhesion effect of those combined polypeptides, after adhesiolys. The concentration of tPA, PAI-1 and active TGFb1 in biopsies from adhesions, unharmed peritoneum before and after adhesiolysis, was also investigated.
\end{abstract}

Materials and methods: $A$ total of 24 male rats were divided in three groups $A(N=8), B(N=8)$ and $C(N=8)$. All rats underwent primary adhesion creating surgery at day 0 , and adhesiolysis at day 7 . Adhesions were evaluated at day 7 and 14, where group B received PL/PG after surgery at day 0 and after adhesiolysis at day 7 , and group $C$ received PL/PG after adhesiolysis at day 7 . Tissue plasminogen activator (tPA), Plasminogen activator inhibitor 1(PAI-1) and active transforming growth factor beta 1(TGF- $\beta 1$ ) were collected from biopsies of adhesions and normal peritoneum at day 0,7 and 14 .

Results: Significant reduction of adhesions $p<0.05$ was seen in group $B$ at day 7 after primary surgery, and at day 14 after adhesiolysis. Significantly $p<0.05$ reduction of adhesions was seen at day 14 after adhesiolysis in group C. Some variations were seen in TPA, PAI-1 and active TGFb1.

Conclusions: PL/PG may be used to prevent adhesion formation after adhesiolysis. The process of fibrinolysis and fibrosis was not affected, after PL/PG prophylaxis and adhesiolysis.

Keywords: Abdominal adhesions; Prevention; Polypeptides; Adhesiolysis

\section{Introduction}

Abdominal adhesions constitute major health related problems, both for the individual patient, and globally due to large expenditures for the healthcare $[1,2]$. Most of the abdominal adhesions form due to previous peritoneal damage, mainly during abdominal surgery, and may end up causing intestinal obstructions, pain and female infertility, along with other complications $[3,4]$.

The overall picture of how abdominal adhesions develop is quite clear, although some parts remain to be elucidated.

Abdominal adhesions form as a result of peritoneal injury. Peritoneum is a serous delicate organ, lining the abdominal cavity, with both protective and restorative functions [5]. Peritoneum consists of a single layer of loosely attached mesothelial cells, resting on a basal lamina and a submesothelial area. The submesothelial area contains resident cells, capillaries and lymphatic vessels [6].

Mesothelial cell detachment is an immediate consequence of peritoneal damage of any kind, leading to serosanguinous leak in the area, forming a fibrin mesh between injured peritoneal sites. The fibrin is usually resolved due to local fibrinolysis, however during extensive trauma and local tissue hypoxia, the fibrin strands may persist, leading to stable adhesions through deposition of collagen and other extracellular matrix proteins [7-9].

One important factor initiating fibrinolysis via the serine protease plasmin in previous damaged peritoneum is the Tissue plasminogen activator (tPA), stored in great quantities in endothelial and mesothelial cells on the peritoneum [10]. Plasminogen activator inhibitor (PAI1 ), on the other hand, is an important factor impairing fibrinolysis through inhibition of tPA $[11,12]$.

The production of collagen and other extracellular matrix proteins in damaged peritoneum is mostly governed by fibroblasts and active transforming growth factor beta 1 (TGF- $\beta 1$ ) [13].

Many attempts have been made during the past years to prevent postoperative adhesions, although none have been feasible in every aspect. The group has focused on combining positively charged polymers, Poly-L-lysine (PL) with negatively charged polymers, PolyL-Glutamate (PG), forming a bioactive, nontoxic, degradable polymer that seals of the injured peritoneal site, prohibiting fibrin deposition and eventually, the development of postsurgical abdominal adhesions. Previous studies have focused on comparing the anti adhesion effects in the abdomen after the primary surgery, when administering the PL/ PG complex [14-16].

However, a huge amount of patients undergoes repeated surgical procedures in the abdomen, causing extensive adhesions, which often forces the surgeons to perform intra abdominal adhesiolysis, thereby increasing the risk of complications such as bleedings, fistulas, abscesses and more [17-20].

In this study, the examination of the potential anti adhesion effect of PL/PG after adhesiolysis was focused. Key parameters i.e. tPA, PAI1 and active TGFb1 in biopsies from normal peritoneum and biopsies

*Corresponding author: Bobby Tingstedt, Institution for Clinical Sciences, Lund University, Department of Surgery, University Hospital of Skåne at Lund, Getingevägen 4, 22185 Lund, Sweden, Tel: +46-46171434; E-mail: Bobby.tingstedt@med.lu.se

Received October 09, 2012; Accepted November 16, 2012; Published November 20, 2012

Citation: Akerberg D, Posaric Bauden M, Isaksson K, Andersson R, Tingstedt B (2012) Prevention of Adhesions by PL/PG after Adhesiolysis. J Tissue Sci Eng 3:121. doi:10.4172/2157-7552.1000121

Copyright: (c) 2012 Akerberg D, et al. This is an open-access article distributed under the terms of the Creative Commons Attribution License, which permits unrestricted use, distribution, and reproduction in any medium, provided the original author and source are credited. 
of adhesions were measured, before and after adhesiolysis, in order to disclose possible differences in the aspects of fibrinolysis or fibrosis.

\section{Materials and Methods}

\section{Animals}

A total of 24 male Sprague Dawley rats (Charles River, Sulzfeld, Germany), weighing approximately $250 \mathrm{~g}$ each were used for induction of peritoneal adhesions The animals were kept under standardized conditions and had free access to water and pellets. The local ethical committee at Lund University approved the adhesion study (Lund Sweden), and the animals received the best animal care, in compliance with the guidelines of the Swedish Government and Lund University, Sweden.

\section{Chemicals}

The chemicals Poly-L-lysine $\mathrm{MW}>30 \mathrm{kDa}(\mathrm{PL})$ and Poly-LGlutamate MW 15-50 kD (PG) (Sigma Aldrich ${ }^{\mathrm{rwx}}$, St. Louis, Missouri, USA) were freshly prepared at the day of the experiment, with $2.54 \%$ glycerol and water, in order to create an osmotic balanced solution to a final concentration of $0.5 \%(5 \mathrm{mg} / \mathrm{ml})$. They were put in separate bottle atomizers that administrated $0.5 \mathrm{ml}$ volume with one dose.

\section{Model}

The animals were anesthetized with $50 \mathrm{mg} / \mathrm{kg}$ Ketalar (Parker Davis $^{\text {Tx }}$ Detroit, Michigan, USA) and Xylazine $6 \mathrm{mg} / \mathrm{kg}$ (Rompun Vet, Bayer AB, Gothenburg, Sweden), by an intramuscular injection. The abdomen was opened through a midline incision, during sterile conditions. A standardized animal adhesion model, lateral incision of the peritoneum, was used, described and validated previously [21]. In brief, a $10 \mathrm{~mm}$ long incision was made in the lateral abdominal wall, including the whole parietal peritoneum through to the muscle underneath. The incision was stitched with interrupted sutures $(60$ Prolene $^{\text {Tw }}$ Ethicon, Somerville, NJ, USA). Treatment was then applied by first spraying the PL and thereafter, PG followed by abdominal closure, using a running suture (Prolene ${ }^{\mathrm{m}} \mathrm{4}-0$, Ethicon, Somerville, NJ, USA) in two layers. Controls received saline $\mathrm{NaCl}$. The animals received subcutaneous saline $(0.9 \%, 5 \mathrm{ml})$ for resuscitation, and buprenorphine for postoperative pain control. All animals were weighed in conjunction with every operative procedure.

\section{Experimental design}

The rats were randomly and blindly divided at the beginning of the experiment into three different groups, according to table 1.

At day 0, biopsies were taken from peritoneum on contralateral (opposite) side to the adhesion creating surgical side. Thereafter, adhesion creating surgery was performed, described in detail above, followed by treatment with either $\mathrm{NaCl}$ or PL/PG, according to table 1 .

At day 7, adhesions were evaluated and scored, biopsies from the formed adhesions and from peritoneum not subjected to surgery (opposite site) were collected. Adhesiolysis were performed, and the groups were again treated, with either $\mathrm{NaCl}$ or $\mathrm{PL} / \mathrm{PG}$ as seen in table 1 .

At day 14, adhesions were evaluated and scored, biopsies from the formed adhesions and biopsies from peritoneum not subjected to surgery (opposite site) were collected.

\section{Evaluation of adhesions}

The length of the adhesions as well as the length of the lateral incisions was measured with a metal calliper, and adhesions were calculated as ratios between these two values. The quality of the adhesions were graded according to a scale developed by Bothin et al. [22].

At day 14, the animals were anesthetized, evaluated, and finally euthanized by an overdose of Ketalar, Rompun, according to AVMA guidelines on euthanasia 2007 [23], whilst still under anesthesia.

\section{Samples}

Biopsies from adhesions and peritoneum were taken, immediately allocated to tubes, and snap frozen to $-80^{\circ} \mathrm{C}$. Tissue samples were homogenized in acetate buffer, in order to extract the proteins efficiently [24]. Active proteins were normalized to total protein content. TPA, PAI- 1 and active TGF- $\beta 1$ levels were determined using ELISA techniques, all according to the manufacturer's instructions.

\section{Histology}

Peritoneal biopsies from the same area were taken on day 7 and day 14 , in order to stain for inflammatory cells (Haematoxylin and Eosin), in order to visualize the complex embedded in the mesothelial/submesothelial space. Prior to staining, the biopsies were treated with acetaldehyde, fixated in alcohol, paraffin embedded, and cut with a microtome.

\section{Statistical analysis}

Results were shown as mean \pm Standard Error (SE). Mann Whitney' $\mathrm{U}$ test were used to determine differences between the groups, both regarding adhesions, as well as tPA, PAI- 1 and active TGFb1. $\mathrm{P}<0.05$ were considered significantly. The statistical analyses were performed with SPSS used for analysis (SPSS v17.0, SPSS Inc., Chicago, Ill., US).

\section{Results}

\section{Adhesions}

Adhesions were significantly lower at day 7, $\mathrm{p}=0.001$; and day 14 , $\mathrm{p}=0.007$, in group B compared to group A (Figure 1). Significantly less adhesions were observed at day 14 in group $\mathrm{C}$ compared to group $\mathrm{A}$, $\mathrm{p}=0.003$ (Figure 1).

\section{tPA}

Normal peritoneal biopsies: Differences of tPA levels in biopsies from normal peritoneum were seen at day 0, 7 and 14 between group A, $\mathrm{B}$ and $\mathrm{C}$, although none of these were significant (Figure 2).

Biopsies from adhesions: Significantly higher levels of tPa from adhesion biopsies were seen at day 7 in group B compared to group A, $\mathrm{p}<0.05$, and in group $\mathrm{C}$ compared to group $\mathrm{A}$ and $\mathrm{B}$ at day $14, \mathrm{p}<0.05$ (Figure 3).

\section{PAI-1}

5.3.1 Normal peritoneal biopsies: Significantly higher levels of PAI-1 in biopsies from normal peritoneum were seen in group A and

\begin{tabular}{|c|c|c|c|c|}
\hline Group & Animals & Day 0 & Day 7 & Day 14 \\
\hline & & Adhesion model & Adhesiolysis & Evaluation \\
\hline A & 8 & $\mathrm{NaCl}$ * & $\left.\mathrm{NaCl} l^{* * *}\right|^{* \star *}$ & $* / * * / * \star *$ \\
\hline B & 8 & PLPG * & PLPG $\left.*\right|^{* *} / * * *$ & $* / * \star / * * *$ \\
\hline C & 8 & $\mathrm{NaCl}$ * & PLPG $* / * * / * * *$ & $* \mid * * / * * *$ \\
\hline
\end{tabular}

Table 1: Peritoneal biopsy collecting tPA, PAl-1 and TGFb1*, adhesion biopsy collecting tPA, PAI-1, TGFb1** Adhesions evaluation ${ }^{\star \star *}$. 
Citation: Akerberg D, Posaric Bauden M, Isaksson K, Andersson R, Tingstedt B (2012) Prevention of Adhesions by PL/PG after Adhesiolysis. J Tissue Sci Eng 3:121. doi:10.4172/2157-7552.1000121

C compared to group B at day $7, \mathrm{p}<0.05$ (Figure 4). Significantly lower levels of PAI- 1 were seen in group B at day 14 compared to group A and $\mathrm{C}, \mathrm{p}<0.05$ (Figure 4 ).

Biopsies from adhesions: Significantly higher levels of PAI-1 from adhesion biopsies were seen at day 7 in group $\mathrm{A}$ and $\mathrm{C}$ compared to group B, $\mathrm{p}<0.05$ (Figure 5). Significantly higher levels of PAI-1 were seen in group $\mathrm{C}$ compared to group $\mathrm{B}$ and $\mathrm{A}, \mathrm{p}<0.05$ at day 14 (Figure $5)$.

\section{Active TGF- $\beta 1$}

Normal peritoneal biopsies: Levels of active TGF- $\beta 1$ from normal peritoneum were significantly higher at day 7 in group $A$ and group $C$ compared to group $\mathrm{B}, \mathrm{p}<0.05$. At day 14 , group $\mathrm{A}$ and $\mathrm{C}$ had significant higher levels of active TGF- $\beta 1$ compared to group $\mathrm{B}, \mathrm{p}<0.05$ (Figure 6).
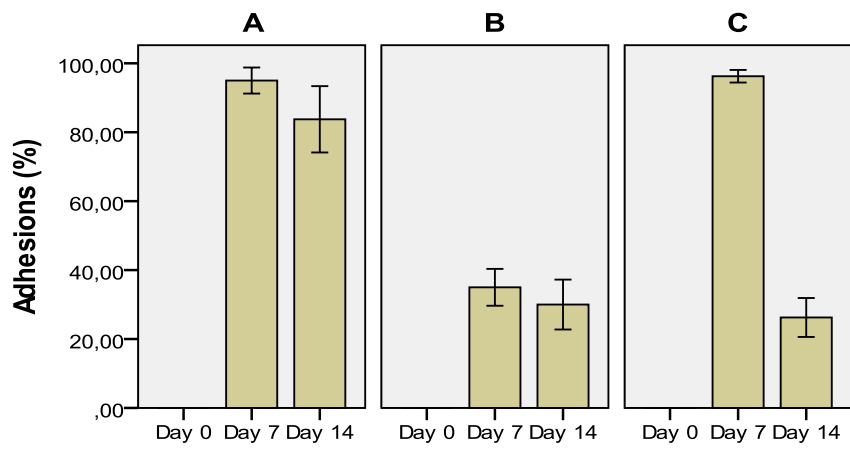

\section{Time}

Figure 1: Adhesions (\%) evaluated at day 7 after surgery and day 14 after adhesiolysis in group A receiving $\mathrm{NaCl}$ before and after adhesiolysis, group $B$ receiving $P L / P G$ before and after adhesiolysis, and group $C$ receiving $\mathrm{NaCl}$ before and PL/PG after adhesiolysis. Significantly, less adhesions at day 7 and 14 in group B compared to group $A(p<0.05)$. There were significantly less adhesions at day 7 and 14 in group $C(p<0.05)$. Graphs show adhesions (mean) \pm SE.
A

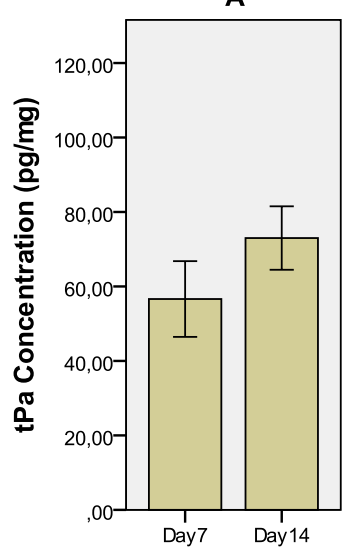

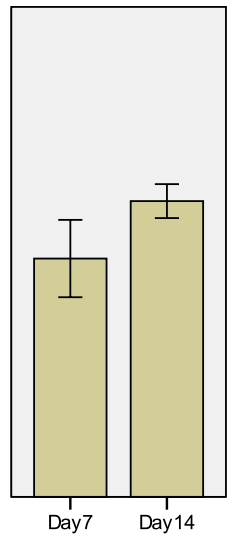

Time
C

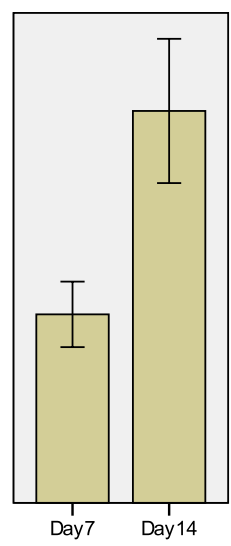

Day7 Day14
Figure 2: Concentrations of tPA (pg/mg) from biopsies of normal peritoneum (contralateral to the surgery site) taken at day 7 (after surgery) and day 14 (after adhesiolysis) in group $\mathrm{A}$, receiving $\mathrm{NaCl}$ before and after adhesiolysis, group $B$ receiving $P L / P G$, before and after adhesiolysis, and group $C$ receiving $\mathrm{NaCl}$, before and PL/PG after adhesiolysis. Graphs show concentrations (mean) \pm SE.

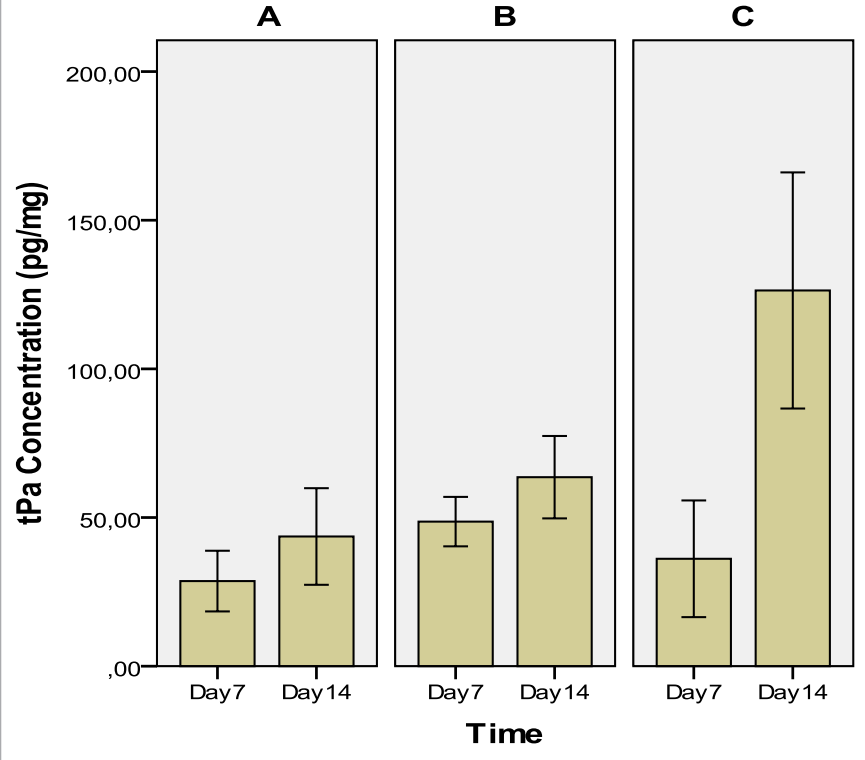

Figure 3: Concentrations of tPA (pg/mg) from biopsies of adhesions at day 7 (after surgery) and at day 14 (after adhesiolysis) in group $\mathrm{A}$, receiving $\mathrm{NaCl}$ before and after adhesiolysis, group $B$ receiving PL/PG before and after adhesiolysis and group $\mathrm{C}$ receiving $\mathrm{NaCl}$, before and $\mathrm{PL} / \mathrm{PG}$ after adhesiolysis. Graphs show concentrations (mean) \pm SE.

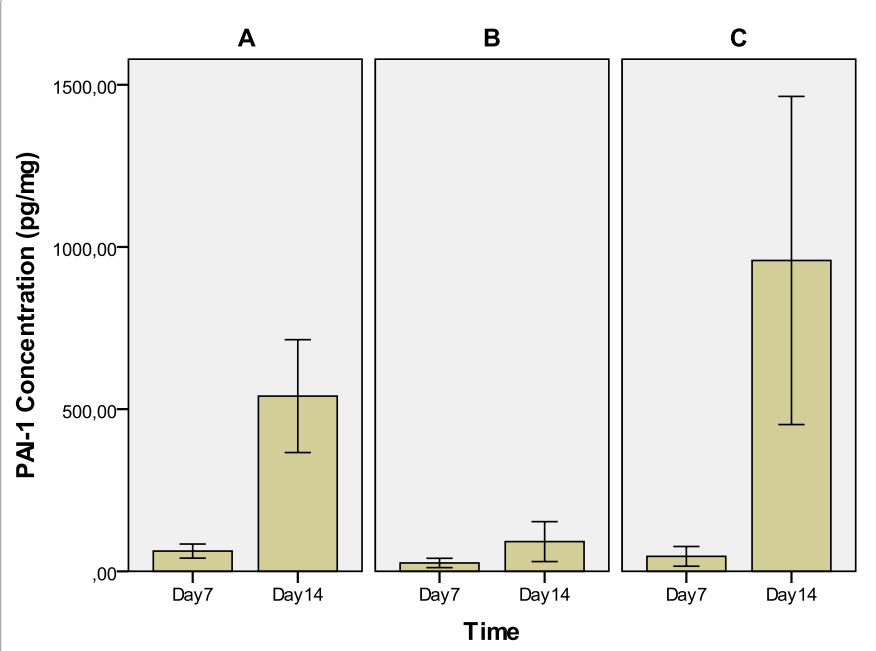

Figure 4: Concentrations of PAl-1 (pg/mg) from biopsies of normal peritoneum (contralateral to the surgery site) taken at day 7 (after surgery) and day 14 (after adhesiolysis) in group $\mathrm{A}$, receiving $\mathrm{NaCl}$ before and after adhesiolysis, group $B$ receiving $P L / P G$ before and after adhesiolysis, and group $C$ receiving $\mathrm{NaCl}$ before and PL/PG after adhesiolysis. Graphs show concentrations (mean) \pm SE

Biopsies from adhesions: Active TGF- $\beta 1$ from biopsies of adhesions in group $\mathrm{B}$ were significantly higher than in group $\mathrm{A}$ and $\mathrm{C}$ at day $14, \mathrm{p}<0.05$ (Figure 7).

\section{Adhesion score}

Significant lower adhesion score were seen at day 7 in group $\mathrm{B}$ compared to group A and C, $\mathrm{p}<0.05$ (Figure 8). Significant lower adhesion score were seen in group $\mathrm{C}$ compared to group $\mathrm{A}$ at day 14 (Figure 8). 
Citation: Akerberg D, Posaric Bauden M, Isaksson K, Andersson R, Tingstedt B (2012) Prevention of Adhesions by PL/PG after Adhesiolysis. J
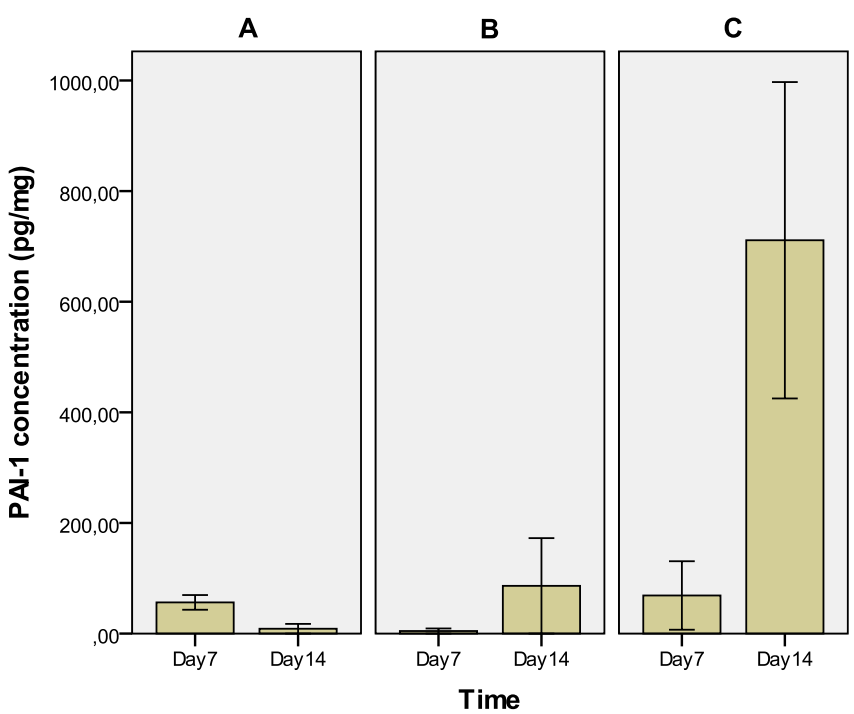

Figure 5: Concentrations of PAl-1 (pg/mg) from biopsies of adhesions at day 7 (after surgery) and at day 14 (after adhesiolysis) in group A, receiving $\mathrm{NaCl}$ before and after adhesiolysis, group B receiving PL/PG before and after adhesiolysis, and group $\mathrm{C}$ receiving $\mathrm{NaCl}$ before and PL/PG after adhesiolysis. Graphs show concentrations \pm SE.

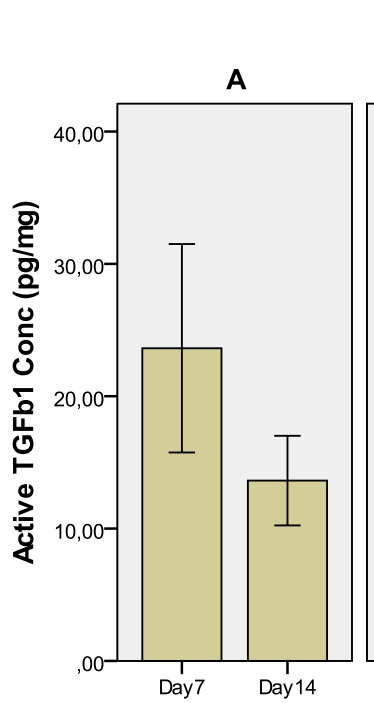

\section{Group}

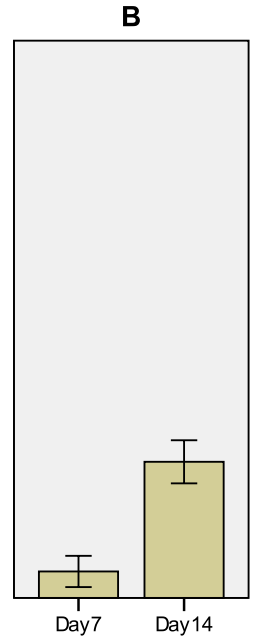

Time

Figure 6: Concentrations of active TGF- $\beta 1(\mathrm{pg} / \mathrm{mg})$ from biopsies of normal peritoneum (contralateral to the surgery site) taken at day 0 before (surgery), at day 7(after surgery) and day 14 (after adhesiolysis) in group A, receiving $\mathrm{NaCl}$ before and after adhesiolysis, group $\mathrm{B}$ receiving PL/PG before and after adhesiolysis, and group $\mathrm{C}$ receiving $\mathrm{NaCl}$ before and $\mathrm{PL} / \mathrm{PG}$ after adhesiolysis. Graphs show concentrations (mean) \pm SE.

\section{Histology}

Histology shows less inflammatory cells surrounding the PL/PG complex (Figure 9). Macroscopical appearance is also disclosed (Figure $10)$.

\section{Discussion}

In this article, it was demonstrated that PL/PG administered locally on peritoneum after adhesion creating surgery at day 0 and after adhesiolysis at day 7 in group B, significantly reduced adhesion
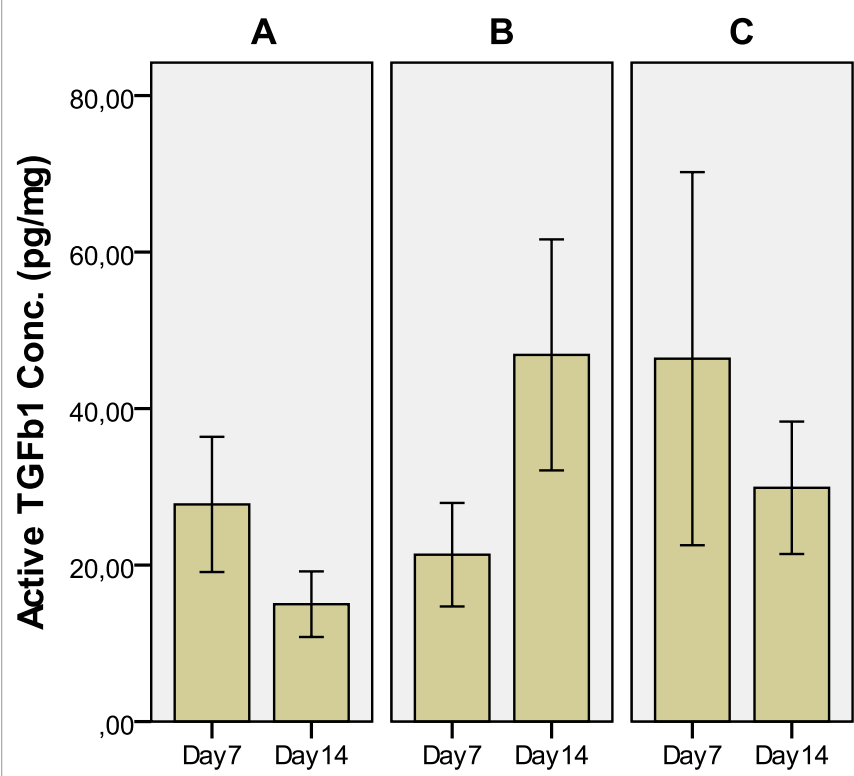

Time

Figure 7: Concentrations of active TGF- $\beta 1(\mathrm{pg} / \mathrm{mg})$ from biopsies of adhesions at day 7 (after surgery), and at day 14 (after adhesiolysis) in group A, receiving $\mathrm{NaCl}$ before and after adhesiolysis, group $\mathrm{B}$ receiving PL/PG before and after adhesiolysis, and group $\mathrm{C}$ receiving $\mathrm{NaCl}$ before and $\mathrm{PL} / \mathrm{PG}$ after adhesiolysis. Graphs show concentrations (mean) \pm SE.
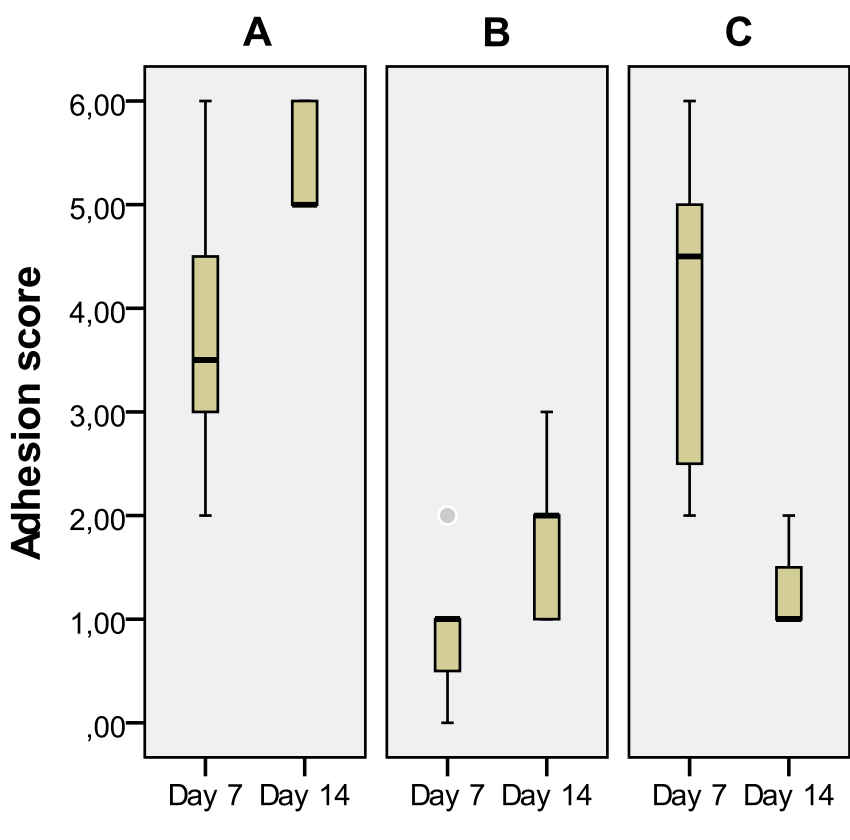

\section{Time}

Figure 8: Adhesion score graded according to Bothin et al. [22] in group A receiving $\mathrm{NaCl}$ before and after adhesiolysis, group $B$ receiving $P L / P G$ before and after adhesiolysis, and group $\mathrm{C}$ receiving $\mathrm{NaCl}$ before and PL/PG after adhesiolysis. Graphs show (median) \pm interquartile range. 


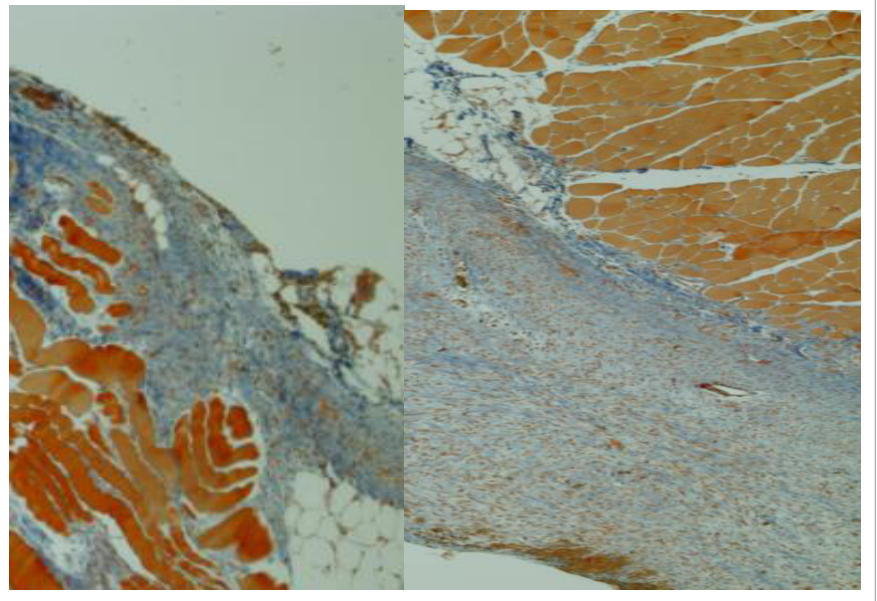

Figure 9: Histology of adhesion area, with and without PL/PG complex. A shows less fibrosis (treatment with PL/PG), than $B$.

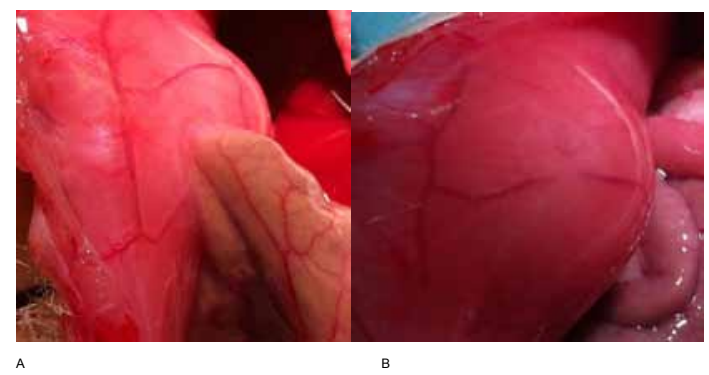

Figure 10: Animal treated with saline $(A)$ and PLPG treated animal $(B)$ at day 14 . In the control, the cecum is totally adhered to the lateral abdominal wall, whereas in the treated animal a smooth and healed peritoneum is noted (white/transparent area in picture).

formation compared to group A, where the same procedure was made, but no PL/PG was given (Figure 1).

Interestingly, PL/PG also significantly reduced adhesions in group $\mathrm{C}$ at day 14 , when administered after adhesiolysis at day 7 (Figure 1).

The results indicate that PL/PG may be used both as adjuvant therapy during primary surgery, to avoid future adhesions, but also in relaparotomy after adhesiolysis, to diminish further adhesions.

In group B, slightly fewer adhesions were seen at day 14 , compared to day 7. Although the difference between these time points was not significant, it was speculated that larger groups would show a significant difference, which would imply an existence of some synergistic effect in readministering the $\mathrm{PL} / \mathrm{PG}$, if the relaparotomy is performed within a week (Figure 1). This is an interesting theory, since most adhesions are formed within 7 to 8 days postoperatively $[25,26]$.

In order to detect possible variations, before and after adhesiolysis, regarding the restorative process of peritoneum between the three groups, the substances involved in fibrinolysis (tPA and PAI-1) and fibrosis (TGF- $\beta 1$ ) were measured, both from normal peritoneum (contralateral to the operated peritoneal site) and in biopsies of formed adhesions.

tPA in biopsies from normal peritoneum taken at contralateral peritoneum (opposite site to primary surgery and adhesiolysis) showed similar patterns in all three groups (Figure 2).
Previous immunohistochemistry studies of peritoneum have shown evidence that tPA is stored in large quantities in endothelial cells, located in submesothelial capillaries, and might be released whenever peritoneum is harmed, even though the damage may be located elsewhere in the peritoneum [27-30].

It was hypothesized based on this and the data that the gradually increasing tPA levels seen in the peritoneal biopsies of unharmed peritoneum, might represent a source of tPA to the contralateral side subjected to surgery. It was further speculated that PL/PG did not affect the levels of tPA in the peripheral peritoneum.

Adhesions differed between the groups, not only in amount, but also in quality (Figure 8). In group A, they were solid and hard, but in group B, they were filmy and smooth, both at day 7 and 14, and loose and filmy in group $\mathrm{C}$ at day 14 .

Levels of tPA in biopsies from adhesions before and after adhesiolysis were increased at day 7 in group $B$ compared to $A$, and at day 14 in group $\mathrm{C}$ compared to group $\mathrm{A}$ (Figure 3 ). It was concluded that there might have been a more pending fibrinolysis in group $\mathrm{B}$ at day 7, compared to group $\mathrm{A}$ and $\mathrm{C}$ at the same time. The higher levels of $\mathrm{tPa}$ at day 14 in group $\mathrm{C}$ to group $\mathrm{A}$ could represent a rebound effect in fibrinolysis, supported in literature [31]. The reason for lower levels of tPa at day 14 in group $\mathrm{B}$ compared to $\mathrm{C}$ could be due to a partial sealant effect of the PL/PG in group (Figure 3).

PAI-1 is located in the submesothelial area in a normal resting state of peritoneum. Whenever peritoneal injury occurs, PAI-1 is increased, produced by several cells involved in the injury and restorative peritoneal process. Some of those are mesothelial cells and PMN cells activated by cytokines, such as IL1 and TNFa $[32,33]$.

In biopsies from normal peritoneum, increasing levels of PAI1 in all three groups was seen. It was concluded that the unharmed peritoneum might have been affected indirectly by the trauma from the contralateral side, thereby the elevating levels. Interestingly, lower levels were seen in group B at both day 7 and 14, which could reflect a lower impact of the surgical trauma in that group (Figure 4).

In biopsies from peritoneal adhesions, similar levels at day 7 between group A and 7 were seen, which could represent the similar amount and quality of adhesions (Figure 1 and 8). This is in conjunction with lower levels of PAI-1 in group B at this time. The higher level of PAI-1 at day 14 is hard to explain, although it could represent a result of higher tPA levels, since PAI-1 is known to form complex with tPa $[7,11]$. In fact, higher levels of tPA were seen at day 14 in group $C$ that paralleled the higher PAI-1 levels at this time (Figure 3).

An important factor to consider when measuring peritoneal adhesions is the remodelling of Extracellular Matrix (ECM), since this is a central part in wound healing. TGF- $\beta 1$ has been shown to be a key regulator in remodelling of ECM [34]. TGF- $\beta 1$ exists in three latent isoforms (TGF- $\beta 1-3)$ that are activated through proteolysis, during peritoneal injury. Here, active TGF- $\beta 1$ was measured, that is known to pose a key role in the formation of adhesions [35].

Peritoneal biopsies from unharmed peritoneum in our three groups also showed some variations, within and between the groups. When the biopsies were taken from unharmed peritoneum at different time points, they had to be taken a bit separated from each other, in order to avoid fibrosis and possible false to high levels of active TGF- $\beta 1$. Thus, it was interpreted that the different levels of active TGF- $\beta 1$ showed in figure 6 may have partly, been a result of separated biopsies [36]. It was further hypothesized that the smaller amounts of active TGF- $\beta 1$ 
in group B at day 7 and 14 compared to group A and C, might have represented a lower fibrotic state in that group, seen as smaller amounts of adhesions (Figure 1).

Biopsies from adhesions showed different levels of active TGF- $\beta 1$, however, none were significant. Group B and C had filmy and loose adhesions at day 7 and 14. Group A had crude and hard adhesions at day 7 and 14 (data not shown). It was speculated (based on this) that active TGF- $\beta 1$ failed to show the difference in quality of adhesions between the groups.

Despite lower adhesions in group B and C at day 14 levels of active TGF- $\beta 1$, in biopsies from adhesions showed higher levels than the control group A at the same time. It could only be speculated that one of the reasons for this could be due to activation through the tPA substance, within the adhesions, since the serine proteases are known to be important activators of latent TGF- $\beta 1$ [37], and tPa is known to be the largest activator of the serine protease plasmin. Higher levels of tPa were in fact seen in at day 14 in both group B and C compared to group A (Figure 3). Biopsies from unharmed peritoneal tissue were not performed in this study, since previous experiments did not reveal any affection of levels of the key parameters studied [38,39].

\section{Conclusions}

In summary, this article shows that PL/PG may be used as an adjuvant after adhesiolysis, performed in the abdomen, in order to avoid future adhesions. The PL/PG complex does not seem to interfere with the normal process of fibrinolysis and fibrosis, when investigated before and after adhesiolysis.

\section{References}

1. Lower AM, Hawthorn RJ, Ellis $H$, O'Brien F, Buchan S, et al. (2000) The impact of adhesions on hospital readmissions over ten years after 8849 open gynaecological operations: an assessment from the Surgical and Clinical Adhesions Research Study. BJOG 107: 855-862.

2. Parker MC, Ellis $\mathrm{H}$, Moran BJ, Thompson JN, Wilson MS, et al. (2001) Postoperative adhesions: ten-year follow-up of 12,584 patients undergoing lower abdominal surgery. Dis Colon Rectum 44: 822-829.

3. Ellis H, Moran BJ, Thompson JN, Parker MC, Wilson MS, et al. (1999) Adhesion-related hospital readmissions after abdominal and pelvic surgery: a retrospective cohort study. Lancet 353: 1476-1480.

4. Cox MR, Gunn IF, Eastman MC, Hunt RF, Heinz AW (1993) The operative aetiology and types of adhesions causing small bowel obstruction. Aust $\mathrm{N} \mathrm{Z} \mathrm{J}$ Surg 63: 848-852.

5. van der Wal JB, Jeekel J (2007) Biology of the peritoneum in normal homeostasis and after surgical trauma. Colorectal Dis 9: 9-13.

6. Suassuna JH, Das Neves FC, Hartley RB, Ogg CS, Cameron JS (1994) Immunohistochemical studies of the peritoneal membrane and infiltrating cells in normal subjects and in patients on CAPD. Kidney Int 46: 443-454.

7. Whawell SA, Vipond MN, Scott-Coombes DM, Thompson JN (1993) Plasminogen activator inhibitor 2 reduces peritoneal fibrinolytic activity in inflammation. Br J Surg 80: 107-109.

8. Vipond MN, Whawell SA, Thompson JN, Dudley HA (1990) Peritoneal fibrinolytic activity and intra-abdominal adhesions. Lancet 335: 1120-1122.

9. Saed GM, Zhang W, Diamond MP (2001) Molecular characterization of fibroblasts isolated from human peritoneum and adhesions. Fertil Steril 75 : 763-768.

10. Stylianou E, Jenner LA, Davies M, Coles GA, Williams JD (1990) Isolation, culture and characterization of human peritoneal mesothelial cells. Kidney Int 37: $1563-1570$

11. Sulaiman H, Dawson L, Laurent GJ, Bellingan GJ, Herrick SE (2002) Role of plasminogen activators in peritoneal adhesion formation. Biochem Soc Trans 30: $126-131$
12. Holmdahl L (1997) The role of fibrinolysis in adhesion formation. Eur J Surg Suppl 24-31.

13. Ghellai AM, Stucchi AF, Chegini N, Ma C, Andry CD, et al. (2000) Role of transforming growth factor beta-1 in peritonitis-induced adhesions. J Gastrointest Surg 4: 316-323.

14. Tingstedt B, Nehéz L, Lindman B, Andersson R (2007) Effect of bioactive polypeptides on leaking large bowel anastomosis and intestines in the rat. $J$ Invest Surg 20: 229-235.

15. Nehéz L, Tingstedt B, Axelsson J, Andersson R (2007) Differently charged polypeptides in the prevention of post-surgical peritoneal adhesions. Scand $\mathrm{J}$ Gastroenterol 42: 519-523.

16. Tingstedt B, Nehez L, Lindman B, Andersson R (2007) Efficacy of bioactive polypeptides on bleeding and intra-abdominal adhesions. Eur Surg Res 39: $35-40$.

17. Sikirica V, Bapat B, Candrilli SD, Davis KL, Wilson M, et al. (2011) The inpatient burden of abdominal and gynecological adhesiolysis in the US. BMC Surg 11 13.

18. Ray NF, Denton WG, Thamer M, Henderson SC, Perry S (1998) Abdominal adhesiolysis: inpatient care and expenditures in the United States in 1994. J Am Coll Surg 186: 1-9.

19. Van Der Krabben AA, Dijkstra FR, Nieuwenhuijzen M, Reijnen MM, Schaapveld M, et al. (2000) Morbidity and mortality of inadvertent enterotomy during adhesiotomy. Br J Surg 87: 467-471.

20. Coleman MG, McLain AD, Moran BJ (2000) Impact of previous surgery on time taken for incision and division of adhesions during laparotomy. Dis Colon Rectum 43: 1297-1299.

21. Holmdahl L, al-Jabreen M, Risberg B (1994) Experimental models for quantitative studies on adhesion formation in rats and rabbits. Eur Surg Res 26: $248-256$.

22. Bothin CG, Okada M, Midtvedt T (1999) Postsurgical adhesion formation in germfree and ex-germfree rats--a study using three scoring scales. J Invest Surg 12: 147-150.

23. http://www.avma.org/issues/animal_welfare/euthanasia.pdf.

24. Holmdahl L, Eriksson E, Risberg B (1997) Measurement of fibrinolytic components in human tissue. Scand J Clin Lab Invest 57: 445-451.

25. Trimbos-Kemper TC, Trimbos JB, van Hall EV (1985) Adhesion formation after tubal surgery: results of the eighth-day laparoscopy in 188 patients. Fertil Steril 43: $395-400$.

26. Sawada T, Hasegawa K, Tsukada K, Kawakami S (1999) Adhesion preventive effect of hyaluronic acid after intraperitoneal surgery in mice. Hum Reprod 14 1470-1472.

27. Holmdahl L, Falkenberg M, Ivarsson ML, Risberg B (1997) Plasminogen activators and inhibitors in peritoneal tissue. APMIS 105: 25-30.

28. Knipe L, Meli A, Hewlett L, Bierings R, Dempster J, et al. (2010) A revised model for the secretion of tPA and cytokines from cultured endothelial cells. Blood 116: 2183-2191.

29. Emeis JJ, van den Eijnden-Schrauwen $Y$, van den Hoogen CM, de Priester W, Westmuckett A, et al. (1997) An endothelial storage granule for tissue-type plasminogen activator. J Cell Biol 139: 245-256.

30. Scott-Coombes DM, Whawell SA, Thompson JN (1995) The operative peritoneal fibrinolytic response to abdominal operation. Eur J Surg 161: 395399.

31. Hellebrekers BW, Trimbos-Kemper GC, Bakkum EA, Trimbos JB, Declerck PJ, et al. (2000) Short-term effect of surgical trauma on rat peritoneal fibrinolytic activity and its role in adhesion formation. Thromb Haemost 84: 876-881.

32. Saed GM, Diamond MP (2003) Modulation of the expression of tissue plasminogen activator and its inhibitor by hypoxia in human peritoneal and adhesion fibroblasts. Fertil Steril 79: 164-168.

33. Whawell SA, Scott-Coombes DM, Vipond MN, Tebbutt SJ, Thompson JN (1994) Tumour necrosis factor-mediated release of plasminogen activator inhibitor 1 by human peritoneal mesothelial cells. Br J Surg 81: 214-216.

34. ten Dijke P, Arthur HM (2007) Extracellular control of TGFbeta signalling in vascular development and disease. Nat Rev Mol Cell Biol 8: 857-869. 
Citation: Akerberg D, Posaric Bauden M, Isaksson K, Andersson R, Tingstedt B (2012) Prevention of Adhesions by PL/PG after Adhesiolysis. J Tissue Sci Eng 3:121. doi:10.4172/2157-7552.1000121

Page 7 of 7

35. Falk P, Bergström M, Palmgren I, Holmdahl L, Breimer ME, et al. (2009) Studies of TGF-beta(1-3) in serosal fluid during abdominal surgery and their effect on in vitro human mesothelial cell proliferation. J Surg Res 154: 312-316.

36. Chegini N, Kotseos K, Zhao Y, Bennett B, McLean FW, et al. (2001) Differentia expression of TGF-beta1 and TGF-beta3 in serosal tissues of human intraperitoneal organs and peritoneal adhesions. Hum Reprod 16: 1291-1300.

37. Lyons RM, Gentry LE, Purchio AF, Moses HL (1990) Mechanism of activation of latent recombinant transforming growth factor beta 1 by plasmin. $\mathrm{J}$ Cell Biol 110: 1361-1367.

38. Akerberg D, Isaksson K, Posaric-Bauden M, Andersson R, Tingstedt B (2012) Effects of polylysine and polyglutamate on inflammation and the norma process of peritoneal healing after surgery. J Tissue Sci Eng 3: 117.

39. Akerberg D, Grunditz C, Posaric-Bauden M, Isaksson K, Andersson R, et al. (2012) The Influence on abdominal adhesions and inflammation in rabbits after exposure to differently charged polypeptides. J Biomed Sci Eng 5: 432-438. 